\title{
Resenha
}

\section{Amizade e ética do cuidado em psicanálise}

\author{
Carlos Augusto Peixoto Junior
}

Oliveira, L. R. P. (2012). O sentido da amizade em Ferenczi: uma contribuição à clínica psicanalítica. Rio de Janeiro, RJ: Uapê.

Sándor Ferenczi (1873-1933), psicanalista contemporâneo de Freud e o mais próximo a ele durante vinte e cinco anos, clínico e teórico de uma agudez extraordinária, sofreu após sua morte, por razões que mesclam circunstâncias históricas e mesquinhez humana, um processo de desprestígio que praticamente o relegou ao esquecimento durante muito tempo. Atacado por alguns colegas, ele chegou a ser considerado um autor que teria se desviado completamente da teoria e da clínica psicanalíticas. Entretanto, desde a publicação de suas obras completas nos anos 1960, um contraste com essa situação anômala vem se estabelecendo, e o interesse por sua vida e sua obra tem crescido de maneira incontestável. E, sem dúvida, não poderia ser de outro modo. Seus escritos estão povoados de achados, controvérsias, críticas e experimentações, que incluem acertos e erros, evidentemente, cuja pertinência não apenas se mantém como também aumenta a cada dia. Nos tempos atuais, já está mais do que evidente que seus escritos constituem um dos mais significativos testemunhos da vitalidade e da curiosidade de um autor audacioso, ao mesmo tempo fecundo e atormentado, que entrou para a história da psicanálise como um dos mais originais dentre a geração de pioneiros da teoria e da prática inventadas por Freud.

Dado o sucesso alcançado ultimamente pela psicanálise ferencziana, já são muitos os comentadores que se dedicaram com afinco ao estudo de seus trabalhos. No entanto, faltava até agora uma pesquisa rigorosa voltada para uma questão subliminar, ainda que extremamente significativa e constante na obra do psicanalista húngaro: a amizade.

1 PUC-Rio, Rio de Janeiro-RJ, Brasil 
É justamente uma investigação como essa que encontramos no trabalho de Luiz Ricardo Prado de Oliveira publicado no ano passado. O sentido da amizade em Ferenczi: uma contribuição à clínica psicanalítica discute detalhadamente esse tema, mencionado com frequência nos artigos do psicanalista húngaro, ainda que ele não tenha se dedicado de maneira sistemática a uma elaboração mais precisa a seu respeito. Considerando com atenção esse aspecto, Prado de Oliveira não pretende propor um juízo cabal quanto às intenções de Ferenczi ao recorrer a expressões do tipo benevolência amistosa ou mesmo amizade no conjunto de sua obra. No que se refere às concepções clínicas ferenczianas, o autor enfatiza que a utilização dessas expressões, estreitamente afinadas com a questão da amizade e com a dimensão clínica do afeto, evidencia a importância da identificação do analista com os mais diferentes aspectos relacionados ao sofrimento do paciente, o que repercute nas diversas experimentações técnicas promovidas por Ferenczi ao longo de sua prática. Prado de Oliveira procura, acima de tudo, destacar o compromisso do discípulo dileto de Freud com a cura de seus pacientes e, nesse sentido, mostra-se atento à dinâmica dos afetos presentes na situação analítica. Além disso, ele também chama a nossa atenção para a importância atribuída por Ferenczi à constituição de parcerias no campo psicanalítico no decorrer de todo o seu percurso profissional, em benefício de um saber voltado para o desvelamento dos mistérios da personalidade humana e da vida como um todo. Nesse contexto, o trabalho destaca ainda a constante preocupação de Ferenczi com a franqueza e a sinceridade, não apenas no âmbito psicanalítico, como também fora dele.

A continuidade de uma trajetória pessoal, em que se destaca a referência ao laço de amizade como um vínculo comprometido com a descoberta da singularidade e com o desvendamento dos mistérios envolvidos na constituição da subjetividade, está ligada, como o autor nos mostra, às matrizes culturais que marcaram a trajetória de Ferenczi, figura dotada de um alto grau de sociabilidade, o que pode ser notado pelos seus relacionamentos com Freud, Rank, Groddeck e Reich dentre outros. Tais relações evidenciam a influência exercida pelos vínculos de amizade na vida do psicanalista húngaro, os quais determinaram diretamente o curso de suas ideias e práticas psicoterapêuticas.

A vida e a obra de Ferenczi, portanto, indicam que ele considerava o vínculo com o outro como algo fundamental para o processo de autoconstituição ética e para a condução de uma prática terapêutica voltada para o reconhecimento das aflições do paciente, de modo a ajudá-lo a se recuperar das feridas causadas pelos traumas emocionais precoces. A comparação entre as diferentes concepções de amizade nas vidas e obras de Freud e Ferenczi, promovida pelo trabalho de Prado de Oliveira, nos ajuda a perceber melhor a enorme importância do afeto amistoso para o psicanalista húngaro. 
A amizade no sentido ferencziano e suas implicações para a clínica também são esclarecidas no livro a partir de uma aproximação com algumas reflexões filosóficas a ela relacionadas, tais como as promovidas por Jaques Derrida e Michel Foucault, comentados a partir da leitura de Francisco Ortega. Na companhia desses filósofos, o trabalho examina a questão da amizade considerando os elementos nela implicados como uma proposta de luta contra o esvaziamento da esfera relacional intersubjetiva na clínica psicanalítica em benefício da análise de aspectos metapsicológicos prioritariamente intrapsíquicos e fantasmáticos. Mais do que isso, o autor também aborda de forma crítica a hegemonia do saber sobre a prática clínica, de forma a oferecer subsídios que habilitem o psicanalista a resistir às frequentes frustrações experimentadas em seu trabalho terapêutico.

Sempre tendo em conta as funções da atividade e da elasticidade na análise - ou da passividade elástica, como dizia Balint -, de modo a contribuir para a construção de um "novo começo" para o analisando, Ferenczi, por diversas vezes, percebeu no analista um amigo. Na medida em que se conceba a prática analítica como uma espécie de jogo que compreende uma parcela de tensão - tal como ele a via -, é fácil notar que os argumentos arrolados no livro de Prado de Oliveira foram indubitavelmente enriquecidos pelas contribuições de Foucault e Derrida, no que elas auxiliam a esclarecer o sentido afetivo e libertário atribuído por Ferenczi à amizade. Trata-se de pensar no psicanalista como um amigo do paciente, ao mesmo tempo próximo e distante. Aí se constitui um movimento ao mesmo tempo de implicação e reserva que exige do analista um bom controle da dimensão contratransferencial. Além disso, Prado de Oliveira também destaca a importância de que ele faça que uma variante afetiva opere na direção do tratamento, de modo a "tocar" o analisando com tato, o que implica ainda que ele resista à tendência a utilizar o saber psicanalítico apenas para atingir o campo restrito e íntimo da história pessoal intrassubjetiva do paciente, voltando-se exclusivamente para o seu passado.

Segundo Ferenczi, o analista não deve temer ser confundido com um amigo pelo analisando, assim como não deve ter medo do agonismo implicado em certos embates eventualmente presentes no processo psicanalítico. Concedendo uma atenção privilegiada ao interjogo da transferência com a contratransferência, ele o relacionou ao investimento libidinal do analista em um paciente que demanda mudanças. Por esse motivo, utilizou um vocabulário bastante específico para descrever a participação do analista nesse interjogo, no qual se destacam expressões como coragem, benevolência, amabilidade e sinceridade. Assim, Ferenczi entendeu que a situação terapêutica deveria ser regida por uma atmosfera amistosa e afetiva, o que sugere que o analista também deva se apresentar ao paciente como uma figura atual que persiste e insiste na 
desconstrução do superego e que, para isso, precisa ser capaz de correr riscos abstendo-se de seus interesses narcísicos.

O afeto da amizade na clínica, sugerido pela vida e pela obra de Sándor Ferenczi, implica a proposição de que o analista participe da análise como se ela fosse uma atividade próxima ao brincar, tal como posteriormente a entendeu Winnicott. A amizade do analista adquire assim o sentido de uma mescla entre desejo, ação e criatividade, na qual também estão implicadas distância, não reciprocidade e assimetria. A forma como Ferenczi pensou e praticou a psicanálise, portanto, inclui a disposição afetiva para o estabelecimento de um tipo de amizade com o analisando cuja radicalidade o levou inclusive a adotar a técnica da análise mútua, extensamente comentada em seu Diário clínico. A importância atribuída por ele à amizade também ganhou relevo em contraponto a algumas ideias de Freud, inclusive no que diz respeito às características pessoais de cada um deles.

O livro de Prado Oliveira ressalta ainda a necessidade de considerarmos a eficácia - simbólica ou não - das possibilidades de um cuidado de si terapêutico proporcionado por um analista amigo, dado que ele traz consigo uma forma de respeito pelo sofrimento do paciente. Assim, espera-se do psicanalista as mais diversas posturas no decorrer do tratamento, dentre as quais o autor destaca a da amizade, incluindo nela o seu caráter agonístico. Considerar a influência exercida por certa amizade do analista na subjetividade do analisando remete a prática analítica acima de tudo para a sua dimensão de exterioridade e atualidade, as quais implicam uma ética do cuidado. Nesses termos, uma forma amigável, alternadamente simétrica e assimétrica no contexto relacional, comporta ainda a possibilidade de que o trabalho analítico se processe na base de uma nova singularidade clínica.

O que fica evidente após a leitura de $O$ sentido da amizade em Ferenczi é que o legado deixado por este mestre pioneiro, que foi chamado de enfant terrible da psicanálise, nos mostra que a singularidade é algo que se encontra no cerne de nossa existência. $E$, nesse sentido, aproveitando o viés filosófico do trabalho aqui comentado, o problema é apreender a singularidade de cada um sem entrar em uma relação de sujeição, tornando-se amigo de um processo possível, como dizia Félix Guattari. Um processo que não remete necessariamente a nenhum complexo universal a respeito da subjetividade, mas que forja sua própria cartografia ao permitir que o indivíduo, de acordo com as situações, reconstitua territórios existenciais lá onde ele se encontrava angustiado e quase desintegrado, reconstruindo ao mesmo tempo suas relações com o mundo de acordo com novas possibilidades de viver. Essa foi uma das principais lições que o mestre húngaro nos deixou; e é um pouco disso que todos os leitores, mais ou menos especializados na obra ferencziana, encontrarão no rigoroso e atento trabalho elaborado por Prado de Oliveira. 
Carlos Augusto Peixoto Junior, professor do Departamento de Psicologia e do Programa de Pós-Graduação em Psicologia Clínica da PUC-Rio. Psicanalista, doutor em Saúde Coletiva pelo Instituto de Medicina Social da UERJ. Autor, dentre outros, de Singularidade e subjetivação: ensaios sobre clínica e cultura (PUC-Rio/7Letras) e de Michael Balint: a originalidade de uma trajetória psicanalítica (Revinter).

Recebido em: 12/06/2013

Aceito em: 14/06/2013 
